\title{
Comparative Study between Mesotherapy and Conventional Systemic NSAIDs in the Treatment of Chronic Low Back Pain with Sciatica
}

\author{
Eman Ahmed Saad ${ }^{1}$, Fatma H. El Nouby ${ }^{1}$, Ghada El Fayomi ${ }^{2}$, Amal Fehr ${ }^{3 *}$, Nehal Ahmed Fathy ${ }^{4}$ \\ Department of Rheumatology, Physical Medicine and Rehabilitation, Faculty of Medicine, \\ Aswan ${ }^{1}$, Mansoura ${ }^{2}$, Helwan $^{3}$, Assiut ${ }^{4}$ Universities, Egypt \\ *Corresponding author: Dr.Amal Fehr, Faculty of Medicine, Helwan University, Egypt. \\ Email; amal.fehr@med.helwan.edu.eg https://orcid.org/0000-0002-3110-5126
}

\begin{abstract}
Background: Chronic low back pain is a common painful medical problem which has significant socioeconomic impact. Conventional pharmacological therapy usually associated with adverse effects. Mesotherapy is the injection of active substances into the surface layer of the skin. This method allows a slower spread, higher levels, and longer lasting effects of drugs in the tissues underlying the site of injection compared with those following intramuscular injection. This technique is useful when a local pharmacological effect is required and relatively high doses of drug in the systemic circulation are not.

Objective: The aim of this study was to compare mesotherapy versus conventional systemic administration of NSAIDs in chronic low back pain with sciatica (radicular pain).

Patients and Methods: Fifty patients were randomized to receive anti-inflammatory therapy according to the following protocols: group I had received ketoprofen $100 \mathrm{mg}(2 \mathrm{ml})+2 \%$ lidocaine $(1 \mathrm{ml})+$ saline $(2 \mathrm{ml})$ for 4 injections. Group II had received: $100 \mathrm{mg}$ ketoprofen orally twice daily.

Results: After receiving treatment (After one and three months; As regarding VAS, repeated measure of the mean VAS score for each group separately showed statistically significant reduction $(\mathrm{P}<0.01)$, and statistically highly significant higher percentage regarding sever grade of disability in group II $(57.1 \%$ and $72.7 \%$; respectively) compared with group I ( $42.9 \%$ and $27.3 \%$; respectively) $(\mathrm{P}<0.05)$.

Conclusion: It could be concluded that the administration of NSAIDs via mesotherapy technique provides better therapeutic benefit than that induced by oral drug administration. That beside the lower drug amounts administered to patients undergoing mesotherapy and the low frequency of administration.

Keywords: Mesotherapy and Conventional Systemic NSAIDs, Chronic Low Back Pain, Sciatica
\end{abstract}

\section{INTRODUCTION}

Low back pain (LBP) is the most frequent type of musculoskeletal pain. It is often recurrent and has important socio-economic consequences (1). Chronic low back pain (CLBP) treatment is usually multimodal and might include medications, rehabilitation, spinal injections, or surgery. The choice of medication depends on the severity, duration, comorbidities and type of pain ${ }^{(2)}$. Nonsteroidal anti-inflammatory drugs (NSAIDs) are the most frequently prescribed medications worldwide and are widely used for patients with low back pain based on their analgesic potential and their anti-inflammatory action ${ }^{(3)}$.

The high frequency of adverse events with NSAIDs (gastrointestinal toxicity, renal dysfunction, cardiovascular complications, and the risk of drug-drug interactions, particularly in older patients with comorbidities) explains the increasingly widespread use of "alternative" treatments ${ }^{(4)}$. Local pharmacological therapy; such as local injectable therapies are effective, well tolerated and represent acceptable alternative to systemic NSAIDs ${ }^{(5,6)}$. Mesotherapy is a minimally invasive technique that consists of Local Intradermal Therapy (LIT) with pharmaceuticals or other bioactive substances given in small quantities through dermal multi-punctures, where the injection site corresponds to the area of the pathological condition ${ }^{(7)}$.

Mesotherapy has been suggested as a treatment for pain relief in musculoskeletal diseases; it is considered as a therapeutic discipline that cannot be ignored as it is widely used in several different specialties and has been the subject of numerous international congresses ${ }^{(8)}$. The objective of this type of administration is to modulate the pharmacokinetics of the injected substance and to prolong the pharmacological effects at a local level. One of the main advantages of mesotherapy is that a local pharmacological effect can be obtained without the need for high systemic concentrations ${ }^{(8,9)}$. In this regard, mesotherapy is recommended to reduce the required dose (and the frequency of administration) of certain analgesics, and at the same time can synergize with other therapies in the management of pain ${ }^{(\mathbf{1 0})}$.

The aim of this study was to compare mesotherapy versus conventional systemic administration of NSAIDs in chronic low back pain with sciatica (radicular pain).

PATIENTS AND METHODS

This prospective comparative study included a total of 50 patients with chronic low 
back pain with sciatica more than 3 months due to prolapsed lumbar disc, spondylolisthesis, or lumbar spondylosis. Patients were presented at Physical Medicine, Rheumatology and Rehabilitation Out-Patient Clinic or referred from Orthopedic Out-Patient Clinic at Aswan University. Approval of the ethical committee and a written informed consent from all the subjects were obtained.

\section{Inclusion criteria:}

1- Patients suffering for more than 3 months of low back pain with radicular pain, with no tributary muscle functional loss.

2- Patients aged above 18 years.

3- Patients had not received neither systemic nor local treatment one week before entrance of the study.

4- Patients had not received physiotherapy one week before entrance of the study.

\section{Exclusions criteria:}

1- Patients have history of cardiovascular, renal, hepatic, gastrointestinal (peptic ulcer), or psychiatric disease.

2- Pregnant woman.

3- Patients with allergy to any of the administered or injected substances.

4- History of coagulation disorders.

Clinical assessment: all patients were subjected to: Full Medical History, thorough clinical examination, pain and functional assessment, radiological investigations. All patients were informed to discontinue any ongoing treatments one week before starting the study.

\section{Patients were divided randomly into two groups:}

○ Group I included 25 patients received NSAIDs mesotherapy sessions which were held once weekly for 4 weeks (a total of 4 sessions).

- Group II included 25 patients received oral NSAIDs therapy in the form of: Ketoprofen: $(100 \mathrm{mg})$ as one capsule twice daily for 4 weeks.

\section{Medications used were as follows:}

ketoprofen $100 \mathrm{mg} / 2 \mathrm{ml}(2 \mathrm{ml})+2 \%$ lidocaine $(1 \mathrm{ml})+$ saline $(2 \mathrm{ml})$.

\section{Technique used:}

1- The nature of the treatment was explained to the patient.

2- Patients were placed in prone position exposing their back.

3- This technique was under complete aseptic condition, proper hygiene and sterilization using ethyl alcohol $70 \%$ and povidineiodine. Figure (1)

4-

- Needle type: sterile, disposable intradermal needle, Lebel's needle (length $4 \mathrm{~mm}$, caliber $27 \mathrm{G}$ ).

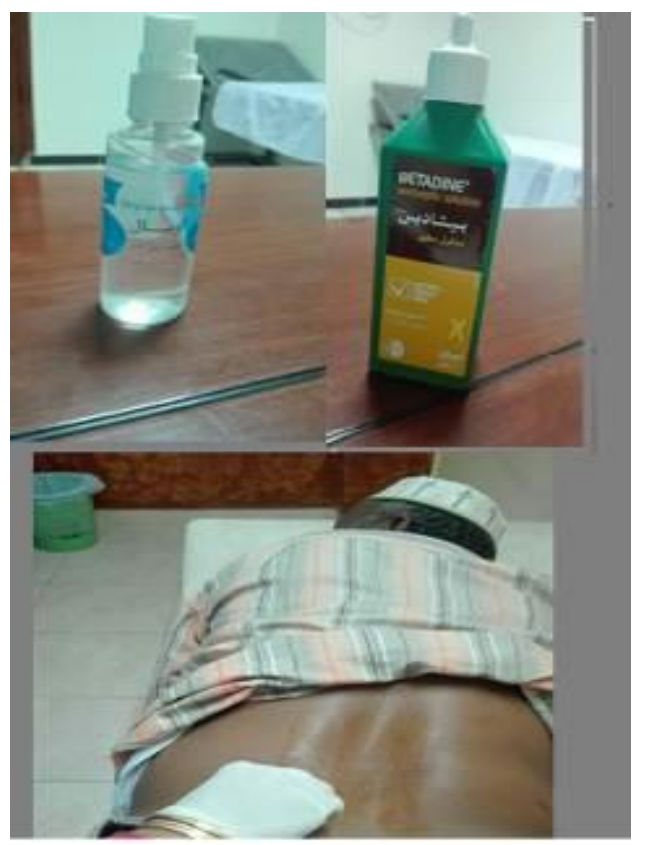

Figure (1) : Steralization by povidoneiodine + Alcohol 70\%

4. Vertebral, Para-vertebral; multiple intradermal microinjections (point by point) were done using $5 \mathrm{cc}$ syringe with Specific needle positioned at 30-45 degree depending on the thickness of the skin, the needle is inserted quickly and gently. In general, $0.10-0.20 \mathrm{ml}$ of product is injected slowly and injection points are usually 2 or $3 \mathrm{~cm}$ in-between; as done by Mammucari et al. ${ }^{(10)}$. Figure (2) 


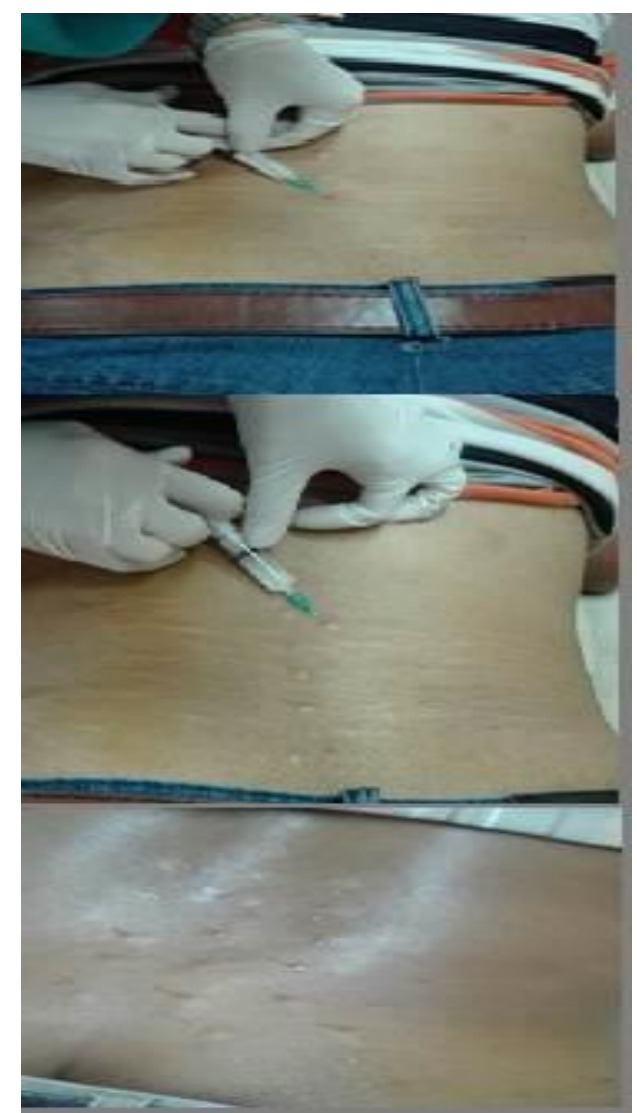

Figure (2): Technique of Injection.

5. Along the running of sciatic nerve: Figure (3)

- POINT 1: 6-7 cm laterally from the posterior median line, $1-2 \mathrm{~cm}$ under the tip of the coccyx.

- It coincides with the acupuncture point U.B. 54.

- POINT 2: point at the midline along the gluteal crease.

- It coincides with the acupuncture point U.B. 36.

- POINT 3: on a line connecting the midpoints of the gluteal transverse crease, $10-12 \mathrm{~cm}$ below the former.

- It coincides with the acupuncture point U.B. 37.

- POINT 4: midpoint of the popliteal transverse crease.

- It coincides with the acupuncture point U.B. 40.

- POINT 5: point midway between POINT 4 and the tip of the heel.

- It coincides with the acupuncture point U.B. 57.

- $\quad$ POINT 6: 3-4 cm inferiorly and posteriorly to the tip of the external malleolus.

- It coincides with the acupuncture point U.B. 61.

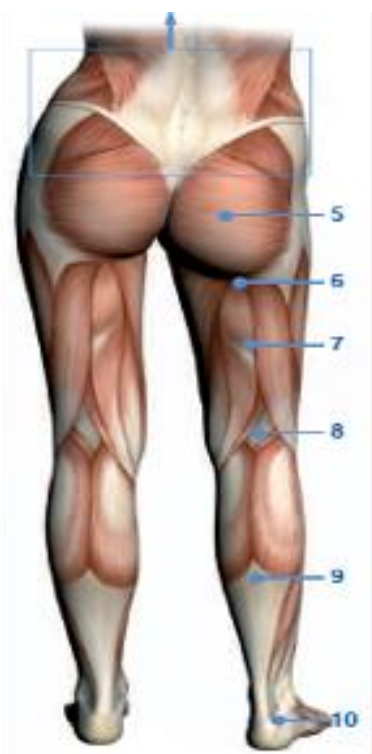

Figure (3): Points along the running of sciatic nerve (A. Ruocco, et al., 2009).

Reassessment of the patients was done at the end of the sessions and two months later by:

a) Physical examination for back ROM.

b) Assessment of pain intensity.

c) Functional assessment.

\section{Statistical analysis}

Data were verified, coded by the researcher and analyzed using SPSS version $21^{*}$. Descriptive statistics: Means, standard deviations, medians and percentages were calculated. Test of significances: chi-square test was used to compare the difference in distribution of frequencies among different groups. For continuous variables; independent t-test analysis was carried out to compare the means. Two-way ANOVA test was carried out to test the association between treatment group and VAS score. A p-value equals or less than 0.05 was considered significant. IBM_SPSS. Statistical Package for Social Science. Ver.21. Standard version. Copyright (c) SPSS Inc., 2011-2012. NY, USA. 2012.

\section{RESULTS}

This study included 2 groups as the following:

Group I (NSAIDs Mesotherapy group): Included 25 patients 19 males and 6 Females with age ranged from 30 to 59 years with mean $\pm \mathrm{SD}(42.8 \pm 8.5)$. Their BMI ranged from 21 to $39 \mathrm{~kg} / \mathrm{m}^{2}$; There were 4 patients with normal BMI and 21 obese patients. As regard $\mathrm{x}$-ray finding there were 3 patients with spondylolisthesis, 5 patients with lumbar spondylosis and 17 patients with possibility of lumbar disc prolapse.

Group II (Oral NSAIDs): included 25 patients, 20 male patients and 5 female patients with age ranged 
from 28 to 62 years with mean \pm SD $(45.4 \pm 10.1)$ (Figure 4 and Figure 5).

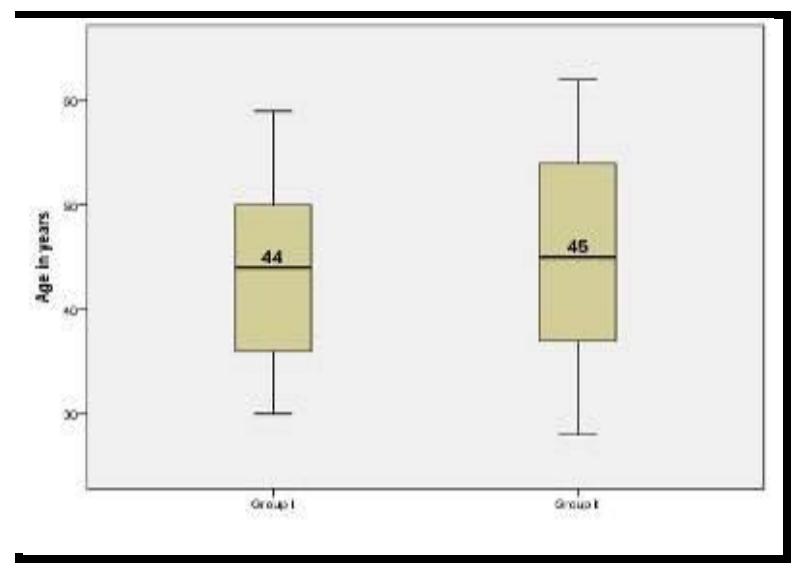

Figure (4): Median Age Differences between Group A and Group B

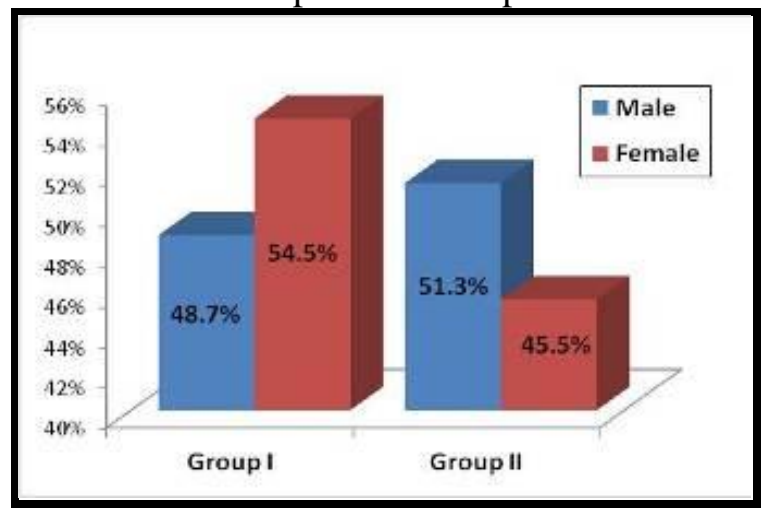

Figure (5): Relationship between Gender and Group

Their BMI ranged from 17 to $32.4 \mathrm{~kg} / \mathrm{m}^{2}$; There were 10 patients with normal BMI and 15 obese patients (Figure 6). As regard $\mathrm{x}$-ray finding there were 1 patient with spondylolisthesis, 7 patients with lumbar spondylosis and 17 patients with possibility of lumbar disc prolapse (Figure 7).
As regards age, sex, body mass index (BMI) and X-ray finding there was no significant difference between the two groups (Table 4).

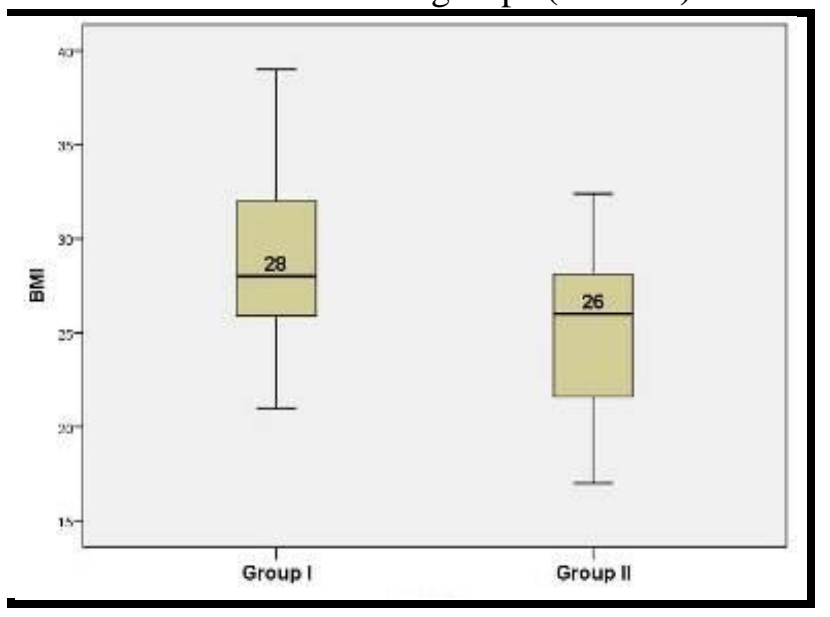

Figure (6): Median BMI between Groups

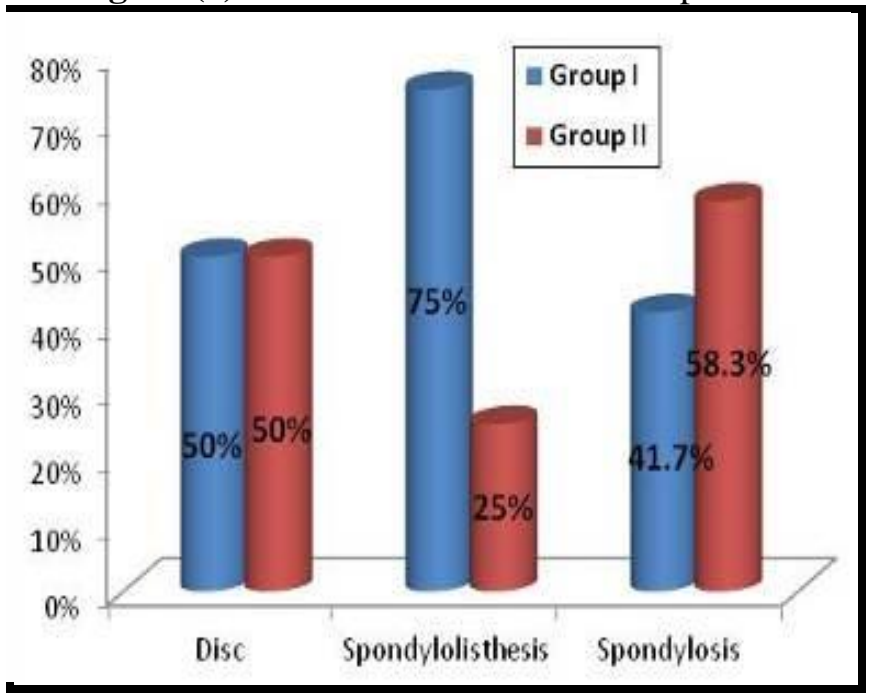

Figure (7): Distribution of the Groups according to the X-ray Finding

Table (4): Comparative Analysis between Groups regarding Demographics

\begin{tabular}{|c|c|c|c|c|}
\hline & & $\begin{array}{l}\text { Group I } \\
(\text { No.=25) }\end{array}$ & $\begin{array}{l}\text { Group II } \\
(\text { No.=25) }\end{array}$ & P-value \\
\hline \multirow[t]{2}{*}{ Age in months } & $($ Mean \pm SD $)$ & $42.8 \pm 8.5$ & $45.4 \pm 10.1$ & \multirow{2}{*}{$=0.354^{*}$} \\
\hline & (Median \& Range) & $44(30-59)$ & $45(28-62)$ & \\
\hline \multirow[t]{2}{*}{ Sex } & Male & $19(48.7 \%)$ & $20(51.3 \%)$ & \multirow{2}{*}{$=0.733 * *$} \\
\hline & Female & $6(54.5 \%)$ & $5(45.5 \%)$ & \\
\hline \multirow[t]{2}{*}{ BMI $\left(\mathrm{kg} / \mathrm{m}^{2}\right)$} & Normal & $4(28.6 \%)$ & $10(71.4 \%)$ & \multirow{2}{*}{$=0.059 * *$} \\
\hline & Obese & $21(58.3 \%)$ & $15(41.7 \%)$ & \\
\hline \multirow[t]{3}{*}{ X-ray Findings } & Disc & $17(50 \%)$ & $17(50 \%)$ & \multirow{3}{*}{$=0.501 * *$} \\
\hline & Spondylolisthesis & $3(75 \%)$ & $1(25 \%)$ & \\
\hline & Spondylosis & $5(41.7 \%)$ & $7(58.3 \%)$ & \\
\hline
\end{tabular}

*T-test was used to compare the mean difference between groups

**Chi-square test was used to compare the difference in proportions between groups 
The result of the Two-way ANOVA test for the association between treatment group and VAS score was depicted in table 5. At baseline; there was statistically non-significant

higher mean VAS score in group II (7.4 \pm $0.9)$ compared with group I $(7.1 \pm 1.1)(\mathrm{P}>0.05)$. After receiving treatment (After one and three months); there was significantly higher mean VAS score in group II $(3.0 \pm 1.4$ and $3.1 \pm 1.2$; respectively) compared with group I ( $1.6 \pm 0.5$ and $1.8 \pm 0.2$; respectively) $(\mathrm{P}<0.05)$. Likewise, repeated measure of the mean VAS score for each group separately showed statistically significant reduction $(\mathrm{P}<0.01)$.

There was statistically significant association between the treatment group and the mean VAS score (baseline vs. after one month vs. after three months) $(\mathrm{P}<0.01)$.

Table (5): Comparative Analysis between Group I and Group II regarding pain VAS score

\begin{tabular}{|c|c|c|c|}
\hline $\begin{array}{l}\text { VAS (Mean } \\
\pm \text { SD) }\end{array}$ & $\begin{array}{l}\text { Group I } \\
(\text { No.=25) }\end{array}$ & $\begin{array}{l}\text { Group II } \\
\text { (No.=25) }\end{array}$ & P-value \\
\hline Baseline & $7.1 \pm 1.1$ & $7.4 \pm 0.9$ & $=0.325^{*}$ \\
\hline $\begin{array}{ll}\text { After } & \text { One } \\
\text { Month } & \end{array}$ & $1.6 \pm 0.5$ & $3.0 \pm 1.4$ & $=0.001 *$ \\
\hline $\begin{array}{ll}\text { After } & \text { Three } \\
\text { Months } & \\
\end{array}$ & $1.8 \pm 0.2$ & $3.1 \pm 1.2$ & $=0.005 *$ \\
\hline P-value & $<0.001 * *$ & $=0.003 * *$ & $=0.005 * * *$ \\
\hline
\end{tabular}

*Test of between groups Effect (T-test analysis)

**Test of Within Group Effect groups (One-way ANOVA(

***Two Way Repeated Measure ANOVA

The result of the Two-way ANOVA test for the association between treatment group and ROM (Flexion) was depicted in table 6.

At baseline; there was statistically nonsignificant higher mean ROM (Flexion) in group II $(4.9 \pm 0.9)$ compared with group I $(4.6 \pm 1.2)(\mathrm{P}>$ $0.05)$.

After receiving treatment (After one and three months); there was non-significantly higher mean ROM (Flexion) in group I (6.7 \pm 1.1 and 6.8 \pm 0.9 ; respectively) compared with group II $(6.6 \pm$ 0.7 and $6.6 \pm 0.8$; respectively) $(\mathrm{P}>0.05)$. But, repeated measure of the mean ROM (Flexion) for each group separately showed statistically significant reduction $(\mathrm{P}<0.05)$. There was statistically significant association between the treatment group and the mean ROM (Flexion) (baseline vs. after one month vs. after three months $)(\mathrm{P}<0.01)$.
Table (6): Comparative Analysis between Group I and Group II regarding ROM (Flexion) results

\begin{tabular}{|l|c|c|c|}
\hline $\begin{array}{l}\text { Flexion in cm } \\
\text { (Mean } \pm \text { SD) }\end{array}$ & $\begin{array}{c}\text { Group I } \\
\text { (No.=25) }\end{array}$ & $\begin{array}{c}\text { Group II } \\
\text { (No.=25) }\end{array}$ & P-value \\
\hline Baseline & $4.6 \pm 1.2$ & $4.9 \pm 0.9$ & $\begin{array}{c}= \\
0.286^{*}\end{array}$ \\
\hline $\begin{array}{l}\text { After One } \\
\text { Month }\end{array}$ & $6.7 \pm 1.1$ & $6.6 \pm 0.7$ & $\begin{array}{c}= \\
0.824 *\end{array}$ \\
\hline $\begin{array}{l}\text { After Three } \\
\text { Months }\end{array}$ & $6.8 \pm 0.9$ & $6.6 \pm 0.8$ & $\begin{array}{c}= \\
0.467 *\end{array}$ \\
\hline P-value & $<\mathbf{0 . 0 0 1}^{* *}$ & $\begin{array}{c}< \\
\mathbf{0 . 0 1 3} * *\end{array}$ & $\begin{array}{c}\mathbf{0 . 0 0 1} * * \\
*\end{array}$ \\
\hline
\end{tabular}

*Test of between groups Effect (T-test analysis)

**Test of Within Group Effect groups (One-way ANOVAC

***Two Way Repeated Measure ANOVA

The result of the Two-way ANOVA test for the association between treatment group and ROM (Extension) was depicted in table 7. At baseline; there was statistically non-significant higher mean ROM (Extension) in group II (3.1 \pm $0.9)$ compared with group I $(2.8 \pm 0.8)(\mathrm{P}>0.05)$. After receiving treatment (After one and three months); there was non-significantly higher mean ROM (Extension) in group II (3.8 \pm 0.6 and $3.6 \pm$ 0.6 ; respectively) compared with group I ( $3.5 \pm 0.7$ and $3.7 \pm 0.6$; respectively) $(\mathrm{P}>0.05)$. But, repeated measure of the mean ROM (Extension) for each group separately showed statistically significant reduction $(\mathrm{P}<0.05)$. There was statistically significant association between the treatment group and the mean ROM (Extension) (baseline vs. after one month vs. after three months) $(\mathrm{P}<0.01)$.

Table (7): Comparative Analysis between Group I and Group II regarding ROM (Extension) results.

\begin{tabular}{|l|c|c|c|}
\hline $\begin{array}{l}\text { Extension in } \\
\text { cm (Mean } \mathbf{\pm} \\
\text { SD) }\end{array}$ & $\begin{array}{l}\text { Group I } \\
\text { (No.=25) }\end{array}$ & $\begin{array}{l}\text { Group II } \\
\text { (No.=25) }\end{array}$ & P-value \\
\hline Baseline & $2.8 \pm 0.8$ & $3.1 \pm 0.9$ & $=0.286^{*}$ \\
\hline $\begin{array}{l}\text { After One } \\
\text { Month }\end{array}$ & $3.5 \pm 0.7$ & $3.8 \pm 0.6$ & $=0.824 *$ \\
\hline $\begin{array}{l}\text { After Three } \\
\text { Months }\end{array}$ & $3.7 \pm 0.6$ & $3.6 \pm 0.6$ & $=0.467 *$ \\
\hline P-value & $<\mathbf{0 . 0 0 1} * *$ & $\begin{array}{c}\mathbf{0} \\
\mathbf{0 . 0 4 1} * *\end{array}$ & $\mathbf{0 . 0 0 1} * * *$ \\
\hline
\end{tabular}

*Test of between groups Effect (T-test analysis( **Test of Within Group Effect groups (One-way ANOVA)

***Two Way Repeated Measure ANOVA 
The result of the Two-way ANOVA test for the association between treatment group and ROM (Lateral flexion) was depicted in table 8.

At baseline; there was statistically nonsignificant higher mean ROM (Lateral flexion) in group II $(15.6 \pm 1.9)$ compared with group I (15.4 $\pm 2.5)(\mathrm{P}>0.05)$. After receiving treatment (After one and three months); there was non-significantly higher mean ROM (Lateral flexion) in group II $(18.6 \pm 1.9$ and $18.6 \pm 1.8$; respectively) compared with group I $(17.6 \pm 2.4$ and $17.3 \pm 2.3$; respectively) $(\mathrm{P}>0.05)$.

But, repeated measure of the mean ROM (Lateral flexion) for each group separately showed statistically significant reduction $(\mathrm{P}<0.05)$.

There was statistically significant association between the treatment group and the mean ROM (Lateral flexion) (baseline vs. after one month vs. after three months) $(\mathrm{P}<0.01)$.

Table (8): Comparative Analysis between Group I and Group II regarding ROM (Lateral Flexion Angle) results

\begin{tabular}{|l|c|c|c|}
\hline $\begin{array}{l}\text { Lateral } \\
\text { Flexion Angle } \\
\text { (Mean } \pm \text { SD) }\end{array}$ & $\begin{array}{c}\text { Group I } \\
\text { (No.=25) }\end{array}$ & $\begin{array}{l}\text { Group II } \\
\text { (No.=25) }\end{array}$ & $\begin{array}{c}\text { P- } \\
\text { value }\end{array}$ \\
\hline Baseline & $15.4 \pm$ & $15.6 \pm$ & $=$ \\
& 2.5 & 1.9 & $0.286^{*}$ \\
\hline $\begin{array}{l}\text { After One } \\
\text { Month }\end{array}$ & $17.6 \pm$ & $18.6 \pm$ & $=$ \\
\hline $\begin{array}{l}\text { After Three } \\
\text { Months }\end{array}$ & $17.3 \pm$ & 1.9 & $0.824 *$ \\
\hline P-value & 2.3 & 1.8 & $\begin{array}{c}= \\
\end{array}$ \\
& $<$ & $=$ & $<$ \\
& $\mathbf{0 . 0 0 1 * *}$ & $\mathbf{0 . 0 3 9} * *$ & $\begin{array}{c}\mathbf{0 . 0 0 1} \\
* *\end{array}$ \\
\hline
\end{tabular}

*Test of between groups Effect (T-test analysis)

**Test of Within Group Effect groups (One-way ANOVA)

***Two Way Repeated Measure ANOVA

The result of the Two-way ANOVA test for the association between treatment group and Oswestry Low Back Pain Disability Scoring Percentage was depicted in table 9.

At baseline; there was statistically nonsignificant higher mean Oswestry Low Back Pain Disability Scoring Percentage in group II (54.2 \pm 16.9) compared with group I $(50.4 \pm 13.6)(\mathrm{P}>$ $0.05)$.

After receiving treatment (After one and three months); there was non-significantly higher mean Oswestry Low Back Pain Disability Scoring
Percentage in group II ( $31.1 \pm 15.3$ and $31.3 \pm 14.7$; respectively) compared with group I ( $30.3 \pm 13.2$ and $28.6 \pm 13.2$; respectively) $(\mathrm{P}>0.05)$. But, repeated measure of the mean Oswestry Low Back Pain Disability Scoring Percentage for each group separately showed statistically significant reduction $(\mathrm{P}<0.05)$.

There was statistically significant association between the treatment group and the mean Oswestry Low Back Pain Disability Scoring Percentage (baseline vs. after one month vs. after three months) $(\mathrm{P}<0.01)$.

Table (9): Comparative Analysis between Group I and Group II regarding Oswestry Low Back Pain Disability Scoring Percentage

\begin{tabular}{|c|c|c|c|}
\hline $\begin{array}{l}\text { Oswestry Scoring \% } \\
(\text { Mean } \pm \text { SD) }\end{array}$ & $\begin{array}{c}\text { Grou } \\
\text { p I } \\
\text { (No.= } \\
\text { 25) } \\
\end{array}$ & $\begin{array}{l}\text { Group II } \\
(\text { No. }=25)\end{array}$ & $\begin{array}{c}P- \\
\text { value }\end{array}$ \\
\hline Baseline & $\begin{array}{c}50.4 \pm \\
13.6\end{array}$ & $\begin{array}{c}54.2 \pm \\
16.9\end{array}$ & $\begin{array}{c}= \\
0.390 \\
*\end{array}$ \\
\hline After One Month & $\begin{array}{c}30.3 \pm \\
13.2\end{array}$ & $\begin{array}{c}31.1 \pm \\
15.3\end{array}$ & $\begin{array}{c}= \\
0.844 \\
*\end{array}$ \\
\hline After Three Months & $\begin{array}{c}28.6 \pm \\
13.2\end{array}$ & $\begin{array}{c}31.3 \pm \\
14.7\end{array}$ & $\begin{array}{c}= \\
0.844 \\
*\end{array}$ \\
\hline P-value & $\begin{array}{c}< \\
0.001 \\
* *\end{array}$ & $\begin{array}{c}= \\
0.044 * *\end{array}$ & $\begin{array}{c}< \\
0.001 \\
* * *\end{array}$ \\
\hline
\end{tabular}

*Test of between groups Effect (T-test analysis)

**Test of Within Group Effect groups (One-way ANOVA)

***Two Way Repeated Measure ANOVA

The result of Chi-square test to compare the difference in proportions between the two groups regarding grade of disability:

At baseline; as depicted in table $\mathbf{1 0}$ and Figure $\mathbf{2 3}$ the following was concluded: Statistically nonsignificant higher percentage regarding Minimal/Moderate grade of disability in group I (58.3\%) compared with group II (41.7\%). Statistically non-significant higher percentage regarding sever grade of disability in group I (52.4\%) compared with group II (47.6\%).

Also, statistically non-significant higher percentage regarding Crippled grade of disability in group II (58.8\%) compared with group I (41.2\%) $(\mathrm{P}>0.05)$. 
Table (10): Comparative Analysis between Groups regarding Grade of Disability

\begin{tabular}{|c|c|c|c|c|}
\hline 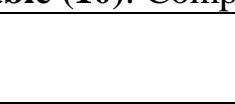 & $x_{2}$ & $\begin{array}{l}\text { Group I } \\
(\text { No.=25) }\end{array}$ & $\begin{array}{l}\text { Group II } \\
(\text { No.=25) }\end{array}$ & P-value \\
\hline \multirow[t]{3}{*}{ At Baseline } & Minimal/Moderate & $7(58.3 \%)$ & $5(41.7 \%)$ & \multirow{3}{*}{$=0.354 *$} \\
\hline & Severe & $11(52.4 \%)$ & $10(47.6 \%)$ & \\
\hline & Crippled & $7(41.2 \%)$ & $10(58.8 \%)$ & \\
\hline \multirow[t]{2}{*}{ One Month } & Minimal/Moderate & $19(52.8 \%)$ & $17(47.2 \%)$ & \multirow{2}{*}{$=0.049 *$} \\
\hline & Severe & $6(42.9 \%)$ & $8(57.1 \%)$ & \\
\hline \multirow[t]{2}{*}{ Three Month } & Minimal/Moderate & $22(56.4 \%)$ & $17(43.6 \%)$ & \multirow{2}{*}{$=0.019 *$} \\
\hline & Severe & $3(27.3 \%)$ & $8(72.7 \%)$ & \\
\hline
\end{tabular}

${ }^{*}$ Chi-square test was used to compare the difference in proportions between groups.

After receiving treatment (After one and three months); as depicted in table 10, the following was concluded: Statistically highly significant higher percentage regarding Minimal/Moderate grade of disability in group I (52.8\% and 56.4\%; respectively) compared with group II (47.2\% and $43.6 \%$; respectively) and statistically highly significant higher percentage regarding sever grade of disability in group II (57.1\% and $72.7 \%$; respectively) compared with group I (42.9\% and 27.3\%; respectively) (P < $0.05)$. There was no evidence of hypersensitivity, allergic reactions, urticaria, erythema or infections in our study.

\section{DISCUSSION}

Few studies have suggested a role of mesotherapy in treatment of chronic low back pain. This motivated us to undertake this trial to use mesotherapy with injectable NSAIDs in the treatment of chronic low back pain with radicular pain.

The current study included 50 patients. As regard age, it was ranged from 28 to 62 with mean of age (42.8 \pm 8.5) in Group I (NSAIDs mesotherapy) and (45.4 \pm 10.1$)$ in Group II (oral NSAIDs) with no significant difference between them.

Lionel et al. ${ }^{(11)}$ found that Individuals who are at risk for low back pain (LBP) are those who are over the age of 30 years and It is the most common cause of disability in individuals between the ages of 45 and 65 years.

As regard VAS score, there was significant difference between group I and group II after receiving treatment $(\mathrm{P}=0.001)$, VAS score reduction was significantly higher among group I $(\mathrm{P}<0.001)$ than group II $(\mathrm{P}=0.003)$. These achieved results denote reduction in VAS due to the efficacy of mesotherapy injections than the oral route.
Our results are similar to the study done by Ciotti et al. ${ }^{(12)}$, which stated that when comparing mesotherapy with lysine acetylsalicylate (49 patients) to mesotherapy with physiologic saline solution (35 patients) in patients with low back pain (as they were injected once a week for 5 weeks), statistically significant improvement were obtained in both groups, and the group treated by mesotherapy with NSAID, showed better results (improvement) compared to placebo group in the reduction of low back pain.

Our results are similar to those of Ruggeri et al. ${ }^{(13)}$ which is a multicentric retrospective study over 984 patients of Cervico-dorsal brachialgia, lumbosacral spinalgia, injected NSAIDs, myorelaxants, and procaine from 3 to 6 weeks, 13 sessions at 1 or 2 week intervals $80 \%$ of patient reported pain reduction by visual scales reported that mesotheraopy is more effective in cervicodorsal brachialgia (87\%).

in Colombo et al. study which is a multicentric prospective open study over 484 patients with acute cervicalgia, lumbar pain, acute myositis, tendinitis, traumatic disorders, shoulderhand syndrome ${ }^{(\mathbf{1 4})}$.

Vasodilators, NSAIDs, myorelaxants, and procaine were injected for 3 sessions of mesotherapy at 3-day intervals revealed that pain reduced in $83.6 \%$ of patients by visual scales.

Our results were similar to those of Piantoni et al. ${ }^{(15)}$ who did a prospective open study over 46 patients with osteo-articular disorders with pain (cervical, dorsal, lumbar column, shoulder, hip, and knee). NSAIDs were injected for 6 sessions of treatment, with 3 days interval, reported that Pain reduction in $78 \%$ of patients by visual scales.

There are some differences between us and Costantino et al. ${ }^{(16)}$ who examined the effects of NSAIDs administered via mesotherapy on low back pain of acute onset. In this study 84 participants with acute low back pain were 
randomized to treatment with either conventional (oral and intramuscular) drug administration $(\mathrm{n}=42)$ or administration of NSAIDs and corticosteroids via mesotherapy technique $(n=42)$, the results showed that both groups improved, with no significant difference in reduction of subjective pain (as assessed by VAS) between the two groups. So, this revealed that administration of NSAIDs via mesotherapy technique results in improvement of subjective pain as oral NSAIDs administration.

In our study we noticed that patients in group NSAIDs mesotherapy showed improvement in ascending manner along the course of the 4 sessions.

Maggiori et al. ${ }^{(17)}$ and Di Cesare et al. ${ }^{(18)}$ also noticed that a large percentage of patients treated with mesotherapy for musculoskeletal pain disorders had rapid pain relief and patients respond within the first three sessions of therapy.

The interpretation of the data regarding back range of motion (ROM) after treatment in the present study, showed Improvement of high statistical significant difference in Group I; NSAID mesotherapy; $(\mathrm{P}<0.001)$ and Group II; Oral mesotherapy; $(\mathrm{P}=0.041)$ compared to pretreatment assessment with more improvement in group I which means a positive therapeutic effect on back ROM which is due to relief of pain and this was in part reflected on movement.

These findings also are similar to the Study done by Sciarra et al. ${ }^{(19)}$, in which 40 patients with cervical pain, randomized in three groups, group 1 (10 patients) has undergone therapeutic exercise 3 times a week for 5 weeks, group 2 (20 patients) has been treated by cervical mesotherapy once a week for 5 weeks using lidocaine $2 \%$, lysine acetyl salicylic acid and physiological solution, and group 3 (10 patients) has undergone both treatments for 5 weeks. Results showed a significant beneficial effect on pain and on increasing the normal activity of everyday life in all treatments in relation to time. The goniometric measurements show an improvement of ROM, statistically significant in relation to time, in all three groups. The study concluded that both mesotherapy and therapeutic exercise, even combined, are valid in reducing chronic neck pain, improving (ROM, personal and social) life of the patient but in the 3rd week there is a slight significant difference in flexion in of group I (Mesotherapy).

Our results were similar to those of Ferrara et al. ${ }^{(20)}$ this retrospective study on 220 records compared the short-term and long-term effects of mesotherapy using a mixture of drugs versus normal saline solution in the treatment of patients with chronic spinal pain (CSP). The result showed statistically significant improvement of ROM in relation to time.

Our patients were followed-up after 3 months and showed maintenance of the results proved by persisted improvement in both groups regarding VAS and $\mathrm{ROM}(\mathrm{P}<0.05)$ and the reduction in VAS score was significantly higher in Group I $(\mathrm{P}<0.001)$ than Group II $(\mathrm{P}=0.003)$.

These finding coincide with the study of Ferrara et al. ${ }^{(20)}$ as it showed at the end of treatment significant improvement $(\mathrm{P}<0.003)$ in both groups, which persisted at the follow-up assessments. At 12 weeks of follow-up, the improvement was significantly greater in patients treated with the drug cocktail than with the saline solution $(\mathrm{P}<0.05)$.

Also, Costantino et al. ${ }^{(16)}$ found that after 6 months VAS score in group A (mesotherapy) was still significantly different from baseline $(\mathrm{P}=0.04)$ and high significant than in group $\mathrm{B}$ (conventional) after 6 months $(\mathrm{P}=0.673)$.

SO, we agree with Paolucci et al. ${ }^{(21)}$ who said that the maintenance of the result at follow-up (after 3 months), certainly strengthens the patient compliance, and thus ensure the ability of mesotherapy to maintain a post therapy effect.

As regard functional disability Oswestry Low Back Pain Disability Scoring (ODI) before treatment showed no significant difference between two groups but after treatment they showed significant reduction in both groups and it was significant in group I $(\mathrm{P}<0.001)$ than in group II $(\mathrm{P}=0.044)$.

Our results are similar to the study done by Di Cesare et al. ${ }^{(18)}$ as its results showed high statistically significant difference in both functional disability questionnaires Ronald Morris Disability Questionnaire (RMDQ) and ODI in comparison to baseline.

In our study we act on points of acupuncture along the course of sciatic nerve (as shown in Figure 3) and found that the site of injection plays a role in the efficacy of mesotherapy. That was proved by Di Cesare $\boldsymbol{e t} \boldsymbol{a l}$. (18) who wanted to compare the effects of triggerpoint (TRP) mesotherapy versus acupuncture-point (ACP) mesotherapy; the study was done on 62 participants with chronic low back pain, lidocaine cloridrate $2 \%$ were injected weekly for four sessions. The results do not show statistically significant differences between the two groups for all measures at the end of the sessions but the ACP group shows significant better outcomes at the follow-up than the ones observed in the TRP group, indicating a better efficacy of the acupoints option in the long term run. 
In our study we use; ketoprofen as NSAID with lidocaine $2 \%$ and saline. This was approved by Foti and Mahmoud (22) as they suggested lidocaine to be the anesthetic of choice for mesotherapy as procaine is quite allergenic and has a short duration of action (15-30 min) comparable to lidocaine which has a moderate duration of action (120 min), good potency, and is the most versatile and safe local anesthetic agent.

It was recommended by Costantino et al. (16) to include corticosteroid to NSAID and lidocaine to be injected on an alternative day in acute LBP. But Foti and Mahmoud ${ }^{(22)}$ found that careful consideration of the relative risk (cutaneous necrosis) and benefits in each patient when using corticosteroid should be required.

Ketoprofen (KPF), as NSAID, was used to compare its anti-inflammatory effect via oral rout and mesotherapy.KPF is a powerful NSAID that is effective whenever administered locally or systemically ${ }^{(23)}$.

The success rate of NSAIDs mesotherapy in our study on chronic low back pain was more than that observed by Costantino et al. ${ }^{(16)}$ as the percentage total dose of NSAIDs to oral is much less in our study, $600 \mathrm{mg}$ in mesotherapy against $6000 \mathrm{mg}$ in patient who receive oral ketoprofen with difference ratio $10 \%$ and is used without adding steroid which is used by Costantino et al. (16).

\section{CONCLUSION}

The present study showed that the administration of NSAIDs via mesotherapy technique provides better therapeutic benefit than that induced by oral drug administration. That beside the lower drug amounts administered to patients undergoing mesotherapy and the low frequency of administration.

Mesotherapy was easily and quickly carried out, well tolerated, with no local or allergic reactions.

Mesotherapy, due to its safety, tolerability, cost effectiveness and efficacy, can be considered a useful technique for the management of painful musculoskeletal diseases and it seems to represent an alternative therapeutic technique especially in the presence of acute, chronic diseases, or comorbidities where there is a high risk of drug interaction, polypharmacy, or when conventional (oral or parenteral) NSAIDs use is contraindicated. Mesotherapy may provide clinical benefits where other therapies are not available/not effective or cannot be used for whatever reason.

\section{REFERENCES}

1- Walker BF (2000): The prevalence of low back pain: a systematic review of the literature from 1966 to 1998. Journal of Spinal Disorders, 13(3): 205-17.

2- Schofferman J, Mazanec D (2008): Evidence informed management of chronic low back pain with opioid analgesics. The Spine Journal, 8: 185-194.

3- Airaksinen O, Brox JI, Cedraschi C et al. (2006): European guidelines for the management of chronic non - specific low back pain. Eur Spine J., 2: 192 - 300.

4- Katz JD, Shah T (2009): Persistent pain in the older adult what should we do now in light of the 2009 American geriatrics society clinical practice guideline? Polskie Archiwum Medycyny Wewnetrznej, 119(12):795-800.

5- Mason L, Moore RA, Edwards JE et al. (2004): Topical NSAIDs for chronic musculoskeletal pain: systematic review and meta - analysis. BMC Musculoskeletal Disorders, 5:28-34.

6- Crosby J (2009): Osteoarthritis: managing without surgery. Journal of Family Practice, 58(7): 354-361.

7- Maggiori S (2004): Manuale di Intradermoterapia Distrettuale. La Mesoterapia in Italia, EMSI, Roma, Italy, https://www.ibs.it/manuale-di-intradermoterapiadistrettuale-mesoterapia-libro-sergiomaggiori/e/9788886669368.

8- Leibaschoff G (2006): Mesotherapy and cellulite. American journal of Mesotherapy, 4: 53. Available from: http: / / www. mesotherapyworldwide.com/ images/ pdf/ AJM _ Vol _ $4_{-} 2006$ _ 53.pdf.

9- Mammucari M, Gatti A, Maggiori S et al. (2011): Mesotherapy, definition, rationale and clinical role: a consensus report from the Italian Society of Mesotherapy. Eur Rev Med Pharmacol Sci., 15(6): 682 $-94$.

10-Mammucari M, Maggiori E, Maggiori S et al. (2014): Low back pain in patients with systemic analgesic intolerance managed with mesotherapy: a case report. J Med Cases, 5(4): 238 - 240.

11-Lionel KA (2014): Risk factors for chronic low back pain. J Community Med Health Educ., 4:2-7.

12-Ciotti C, Laurini A, Tiberti S et al. (2012): Lumbar mesotherapy in the treatment of low back pain. $9^{\text {th }}$ Mediterranean Congress of PRM 40th National Congress. Simfer. Giornale Italiano Di Medicina Riabilitativa, 26: 2 - 3.

13-Ruggeri F, Bartoletti CA and Maggiori S (1981): Clinical results of the multicentric experimentation. Giornale di Mesoterapia, 1: 47-49.

14-Colombo I, Cigolini M, Combi F (1981): Clinical resultsvof the multicentric experimentation. Giornale divMesoterapia, 1: 50-52.

15-Piantoni D, Cotichelli E and Di Gianvito P(1981): Clinical results of the multicentric experimentation. $\mathrm{J}$ Mesother, 1: 60-63.

16-Costantino C, Marangio E, Coruzzi G et al. (2011): Mesotherapy versus systemic therapy in the treatment of acute low back pain: A randomized trial. Evidencebased Complementary and Alternative Medicine, https://www.hindawi.com/journals/ecam/2011/317183 I 
17-Maggiori E, Bartoletti CA, Maggiori S et al. (2010): Local intradermotherapy (ITD) with mesoglican in PEFS and CVLI, retrospective study. Trends Med., 10: 73-78.

18-Di Cesare A, Giombini A, Di Cesare M et al. (2011): Comparison between the effects of trigger point mesotherapy versus acupuncture points mesotherapy in the treatment of chronic low back pain: A short term randomized controlled trial. Complementary Therapies in Medicine, 19:19-26.

19- Sciarra T, Cimatti A, Magni E et al. (2008): Mesotherapy versus analgesic therapeutic exercise in the treatment of chronic neck pain. Europe Medicophysica, 44: 1-3.

20-Ferrara PE, Ronconi G, Viscito $\mathrm{R}$ et al. (2017): Efficacy of mesotherapy using drugs versus normal saline solution in chronic spinal pain: a retrospective study. International Journal of Rehabilitation Research, 40(2): 171-174.

21-Paolucci T, Piccinini G, Trifan PD et al. (2016): Efficacy of trigger points mesotherapy for the treatment of chronic neck pain: a short term retrospective study. Int J Phys Ther Rehab., 2: 113116.

22-Foti C, Mahmoud A (2013): Workshop: Mesotherapy in $8^{\text {th }}$ International conference of physical medicine, rheumatology and rehabilitation. http://www.err.eg.net/article.asp?issn=1110-

$161 \mathrm{X}$; year $=2014$; volume $=41$; issue $=4$; spage $=179$; epag e=186; aulast=Al-Helow;type $=0$

23-UK BEAM Trial Team - United Kingdom back pain exercise randomized trial (2004): Effectiveness of treatments for back pain in primary care. BMJ., 329: 1377. 